\title{
An Evaluation of Pediatric Out Patient Department (POPD) of a Private Dental College Hospital by Accompanying Parents of Child Patients
}

\author{
Khan M A I ${ }^{1}$, Parvin $\mathrm{S}^{2}$, Aman J3 ${ }^{3}$ Mahmud G ${ }^{3}$, Anber N ${ }^{3}$, Chowdhury T G ${ }^{4}$
}

Abstract:

Purpose:The Pediatric Out-patient-department (POPD) of a dental hospital deals with children with different tooth related complaints. Dental treatment of a child patient requires three way interactions between the child, the parent and the dental surgeon. Though health of the patient remains the top priority for caregivers, satisfaction with the delivery system is vital for long lasting doctor-patient relationship. Thepurpose of the study was to evaluate the performance of Pediatric OPD by the accompanying parents of children receiving treatment at the OPD of a private dental college hospital. Methods: A cross sectional study was carried out at the POPD of Sapporo Dental College Hospital, Uttara Model Town of Dhaka city during May-July 2017. Sampling was done by simple random sampling method.Data were collected from the parents of 122 children aged between 1-12 years by using a self-administrated questionnaire. Results: Majority of the participating parents were residents of Uttara Model Town or areas in the vicinity and were employed, educated and are middle are middle socioeconomic class. More than sixty percent (62.3\%) of the respondents were parents of children between 4-7 years of age. More than $90 \%$ of the patients had waiting time at the department between 0-30 minutes. Treatment cost was described as 'low or 'reasonable' by $87 \%$ of the parents. Only $8.2 \%$ mentioned 'unsatisfactory' regarding the cleanliness of Pediatric OPD. More than 95\% of the respondents expressed 'Satisfactory' and 'good' level of satisfaction with general performance of OPD and the treatment provided by the dental team.Conclusion: Parents expressed general satisfaction with the performance of Pediatric Department of Sapporo Dental College Hospital.

Keywords: Parent Satisfaction, Evaluation, Dental, PaediatricOPD

1. Professor (CC) and Head, Dept. of Pediatric Dentistry, Sapporo Dental College and Hospital

2. Assistant Professor, Dept. of Pediatric Dentistry Sapporo Dental College and Hospital

3. Lecturer, Dept. of Pediatric Dentistry Sapporo Dental College and Hospital

4. Associate Professor, Dept. of Pediatric Dentistry, Update Dental College and Hospital

Correspondence : Dr. Md. Asif lqbal Khan, Department of Pediatric Dentistry, Sapporo Dental College and Hospital, Uttara, Dhaka. Email: asifkhan34 @hotmail.com 


\section{Introduction}

Patient satisfaction is one of the most important aspects of clinical dentistry and requires a combined effort and hardwork from the administration and personnel involved. ${ }^{1}$ The psychology of getting good care and value for money along with professionalism of the care givers is key factors for developing good patient-doctor relationship and inspiring the patients returning to the facility for further care in the future. ${ }^{2}$ Catering to the needs of the patients is vital to practice management and client satisfaction. ${ }^{3}$ It has been observed that dissatisfaction with the dentist is the main reason for not going back to the same dentist for further treatment. Studies demonstrated clear association between satisfaction levels, patient compliance and quality of treatment for commercial success of dental health care delivery systems. ${ }^{4,5}$

Children treated at an OPD are accompanied by an attendant commonly by their parents, grandparents, elder siblings or a close relative. A pediatric department is different from other departments for children cannot make a decision on their own and an adult attendant must give consent to the treatment regimen. Not only that the overall environment of the department and the departmental staff, the hospitality, sincerity and caring attitude of the whole dental team along with the child behavior management skills of the dentist is under constant scrutiny of the parents. ${ }^{6}$ The dental team can feel the extra pressure when treating small children partly because of unpredictable nature of the patient and partly the unexpected reaction from a parent, who might become sensitive and react in indiscriminate manner seeing his or her child crying at the chair. ${ }^{7}$ This type of scenario is not uncommon in Paediatric OPD, testing the patience and skill of the caregiver and also making him a manager for crisis situations.

On the other hand, certain factors such as the decoration and cleanliness of the clinic, the waiting time at the reception, the treatment quality and expenses, overall ambience at the clinic among others, might dictate a patient's satisfaction or dissatisfaction level with the caregiver. ${ }^{8}$ Whatever may be the situation, patient health and satisfaction are the top priorities and for this there should be room for constant improvement by working out on every constructive criticism. ${ }^{9,10,11}$ As satisfaction is a most important com- ponent of health service performance evaluation, it is important to know about the different factors which affect patient satisfaction using dental services. Since children are in no position to provide correct evaluation of a departmental performance, their parents are required to use their judgment in evaluating and expressing their satisfaction level of the dental care services provided at the Hospitals.

According to Bangladesh Medical and Dental Council, Sapporo Dental College and Hospital is the only fully fledged dental college in Uttara Model Town, operating since $2002 .^{12}$ The population in and around this model town belong to lower to higher middle class, educated and largely employed. ${ }^{13}$ The general OPD of this hospital receives more than a hundred new patients per day, out of which $18-20 \%$ seek treatment at pediatric OPD. ${ }^{14}$ These children are mostly aged between 1-12 years and only a handful is older. The parent makes the decision about treatment on behalf of the child after consulting with the doctor. It is important to get feedback from the patients about the standard of treatment they are receiving from their point of view for as part of quality improvement and patient satisfaction. Since children are in not mature enough to understand the integral factors of expectation and satisfaction, their parents should evaluate the performance and state their opinion about the care delivery system.Searching through the available documents, we could not retrieve a single paper which evaluated the level of patient satisfaction for pediatric dental treatment provided either ina private or a government institution in Bangladesh. Therefore, this survey was carried out to evaluate the satisfaction level of the parents accompanying the children receiving treatment at Pediatric OPD of Sapporo Dental College Hospital, a private dental hospital at Uttara, Dhaka.

\section{Methods and materials}

This cross-sectional survey was conducted at the PaediatricOPD (POPD) of Sapporo Dental College Hospital, a private dental College located in Uttara Model Town, Dhaka during May-July 2017. A total of one hundred and twenty $(\mathrm{N}=122)$ parents / guardians or accompanying attendants of 122 children aged between 1-12 years, were the study subjects.Parents of patients who had visited the OPD more than once were included as participants of this survey while new 
or first timers were excluded for obvious reasons. A convenience sampling technique was used in this survey. Permission from the hospital authority was obtained before hand and the nature of this survey was explained to the participants prior to the face to face interview. A verbal consent was taken from the parents stating the purpose of the survey and assuring that no harm is expected and the results of the survey would only be used for understanding the parental evaluation of the departmental performance and that confidentiality of the result would be strictly maintained.

A self-administered questionnaire having closed ended components in relevance with the objectives of the study was developed for the survey. The First part of the questionnaire was aimed to obtain socio-demographic data, while the second part specifically asked for parental evaluation of the department's performance.

The survey personnel were trained both theoretically and practically about accurate data collection procedure. Each question was filled up by the parents and the interviewers readily explained if someone could not understand any specific part. The collected data wereanalyzed byword Excel spreadsheet. Data presentation included frequency distribution tables.

\section{Results}

Table 1: Distribution of the parents according to their Socio economic status ( $\mathrm{N}=122)$

\begin{tabular}{|l|l|l|}
\hline Residential address & Frequency & (\%) \\
\hline Inside Uttara Model Town & 65 & 53.3 \\
Outside Uttara Model Town & 38 & 31.1 \\
Outside of Dhaka Metropolitan & 19 & 15.6 \\
area & & \\
\hline Total & 122 & $100 \%$ \\
\hline Parent's Occupation & 59 & 48.4 \\
\hline Service & 40 & 32.8 \\
Business person & 14 & 11.5 \\
House maker/stay home parent & 9 & 7.4 \\
Others & 122 & $100 \%$ \\
\hline Total & \multicolumn{2}{|l|}{} \\
\hline Parent's Education level & 7 & 5.7 \\
\hline Uneducated & 19 & 15.6 \\
Primary to Secondary & 67 & 54.9 \\
Graduate & 29 & 23.8 \\
\hline Post Graduate & 122 & $100 \%$ \\
\hline Total & 20 & 20.5 \\
\hline Parent's/Family's Income & 25 & 35.2 \\
\hline$<10000$ Tk/month & 34 & $100 \%$ \\
\hline $11-20000$ Tk/month & 43 & 122 \\
\hline $21-30000$ Tk/month & \multicolumn{2}{|l}{} \\
\hline$>30000 t k$ Tk/month & Total & \\
\hline
\end{tabular}

Table 1 showed $43.3 \%$ parents lived withinUttara Model Town and $31.1 \%$ lived in the vicinity of Uttara Model town while $15.6 \%$ patient came from Outside Dhaka Metropolitan area. Out of 122 respondents more that $80 \%$ (Service $48.4 \%$ and business (32.8\%) were holding a job or doing business. Fourteen were stay home parents and 9 were occupied otherwise. Almost eighty percent of the parents $(54.9 \%$ graduates and $23.8 \%$ Post graduates) were well educated. Thirty-two( $32 \%$ ) percent parent had a monthly income of more than 30,000 taka, Fifty nine $(n=59)$ parents' income was between 11-30,000 taka per month while 20 parents had an earning of less than taka 10,000 per month

Table 2: Distribution of the patients according to socio-demographic condition ( $\mathrm{N}=122)$

\begin{tabular}{|l|l|l|}
\hline Age of the child & Frequency & \multicolumn{1}{|c|}{ (\%) } \\
\hline $1-3 y r s$ & 7 & 5.7 \\
$4-7 y r s$ & 76 & 62.3 \\
8-12yrs & 39 & 32 \\
\hline Goes to School? & & \\
& & \\
\hline Yes & 105 & 86 \\
No & 17 & 14 \\
\hline Family Type & & \\
\hline Nuclear family & 91 & 74.6 \\
Combined/joint family & 31 & 25.4 \\
& & \\
\hline No. of Siblings & & \\
& & \\
\hline 0 & 40 & 32.8 \\
1 & 24 & 19.7 \\
2 & 40 & 32.8 \\
3 or more & 16 & 13.11 \\
\hline No. of Family & & \\
members & & 26.2 \\
\hline 3 & 32 & 28.7 \\
4 & 35 & 18.2 \\
5 & 23 & \\
6 or more & & \\
\hline
\end{tabular}

Table 2 shows $62.3 \%$ of the children belong to $4-7$ years age group, $86 \%$ attended school and $74.6 \%$ lived in a nuclear family. Almost 33 percent (32.8\%) children belong to single child family. 
Table 3: Opinion of the parents about PaediatricOPD and OPD Services at SDCH $(\mathrm{N}=122)$

\begin{tabular}{|c|c|c|c|}
\hline $\begin{array}{l}\text { OPD services at } \\
\text { SDCH }\end{array}$ & $\begin{array}{l}\text { Opinion of the attending } \\
\text { parents }\end{array}$ & Frequency & \\
\hline $\begin{array}{l}\text { Reason for } \\
\text { visiting the OPD }\end{array}$ & $\begin{array}{l}\text { Routine Check-up } \\
\text { Tooth related Complaints } \\
\text { Follow-up }\end{array}$ & $\begin{array}{l}19 \\
99 \\
4\end{array}$ & $\begin{array}{l}15.6 \\
81.1 \\
3.3\end{array}$ \\
\hline $\begin{array}{l}\text { How did you learn } \\
\text { about } \\
\text { POPD }\end{array}$ & $\begin{array}{l}\text { Advertisement } \\
\text { Referred by others } \\
\text { By own interest }\end{array}$ & $\begin{array}{l}1 \\
57 \\
64\end{array}$ & $\begin{array}{l}0.8 \\
46.7 \\
52.5\end{array}$ \\
\hline Waiting time & $\begin{array}{l}0-15 \text { mins } \\
16-30 \text { mins } \\
30-60 \text { mins } \\
>1 \text { hour }\end{array}$ & $\begin{array}{l}83 \\
27 \\
10 \\
2\end{array}$ & \begin{tabular}{|l|}
68 \\
22.1 \\
8.2 \\
1.6
\end{tabular} \\
\hline Treatment Cost & $\begin{array}{l}\text { Low } \\
\text { Reasonable } \\
\text { Expensive }\end{array}$ & $\begin{array}{l}35 \\
72 \\
15\end{array}$ & $\begin{array}{l}28.7 \\
59 \\
12.3\end{array}$ \\
\hline $\begin{array}{l}\text { Cleanliness of the } \\
\text { dept. }\end{array}$ & $\begin{array}{l}\text { Unsatisfactory } \\
\text { Satisfactory } \\
\text { Good }\end{array}$ & $\begin{array}{l}10 \\
85 \\
27\end{array}$ & $\begin{array}{l}8.2 \\
69.7 \\
22.1\end{array}$ \\
\hline $\begin{array}{l}\text { General } \\
\text { satisfaction with } \\
\text { POPD }\end{array}$ & $\begin{array}{l}\text { Unsatisfactory } \\
\text { Satisfactory } \\
\text { Good }\end{array}$ & $\begin{array}{l}5 \\
86 \\
31\end{array}$ & \begin{tabular}{|l|}
4.1 \\
70.5 \\
25.4
\end{tabular} \\
\hline
\end{tabular}

According to Table 3, Ninety-nine ( $n=99)$ children visited POPD of SDCH with tooth related complaints. Sixty-four ( $n=64,52.5 \%$ ) parents came to the OPD by their own interest while 57 parents visited SDCH being referred by others. Most of the patient's waiting time for treatment were $0-15$ minutes $(68 \%)$ and Seventy-two $(\mathrm{N}=72)$ parents $(59 \%)$ opined that treatment cost were reasonable. Out 122 participants 112 had stated cleanliness of the Pediatric OPD to be satisfactory or good. Only 5 parents expressed general dissatisfaction (4.1\%) with the Pediatric Department.

Table 4: Opinion of parents regarding hospital staff $((\mathrm{N}=122)$

\begin{tabular}{|l|l|l|l|}
\hline $\begin{array}{l}\text { Opinion regarding } \\
\text { Hospital Staff }\end{array}$ & $\begin{array}{l}\text { Level } \\
\text { satisfaction }\end{array}$ & Frequency & $(\%)$ \\
\hline $\begin{array}{l}\text { Patient management } \\
\text { skill of the attending } \\
\text { doctor }\end{array}$ & Snsatisfactory & 5 & 4.1 \\
\hline Skill of the assisting staff & Good & 80 & 65.6 \\
& Unsatisfactory & 6 & 30.3 \\
\hline Satisfactory & 77 & 4.9 \\
Satisfaction with & Good & 39 & 63.1 \\
treatment provided by & Satisfactory & 5 & 4 \\
dental team & Good & 39 & 64 \\
\hline
\end{tabular}

According to Table 4 more than $95 \%$ parents expressed their satisfaction, ranging between satisfactory and good, when asked about patient management skill of the doctor the skill of the assistants
$(95.1 \%)$ and the general satisfaction with treatment provided at the POPD(96\%) respectively. Only 6 patientswere not satisfied with the assisting staffs, 5 parents did not rate the doctors' skill satisfactory and same number of parents did not find satisfaction with overall treatment provided by the dental team.

\section{Discussion}

Sapporo Dental College and Hospital is the only fully fledged dental college in Uttara Model Town, operating since 2002. It is for obvious reasons the parents who accompanied the children mostly belong to Uttara and the areas in its vicinity. Some even came from Outside of Dhaka metropolitan area.

In general, the population of Uttara Model Town belongs to low to higher middle class. With many schools and a number of private and public colleges and a few Private Universities within the town limits, the education level of the inhabitants are expected to be high.13Accordingly the socio-demographic distribution reflected that the parents are generally educated, earn quite a decent income, and majority lived in nuclear families.Parents were generally employed (service holder $48.4 \%$ and business $32.8 \%$ ), with only $18.7 \%$ stay home parents or were doing something else. Majority (86\%) of the children attended school with $62.3 \%$ belonging to 4-7 years age group. Single child families were common (32.8\%) while $54.9 \%$ represented 3-4 member families.

The survey results revealed that majority $(81.1 \%)$ of the patients came to the OPD with various tooth related complaints and the rest for follow-upvisits or routine checkup. According to the parents, they had learnt about Sapporo Dental College Hospital facility by their own interest $(52.5 \%)$ or by reference from others (46.7\%). Only 1 person out of 122 came after seeing an advertisement of the hospital.

Waiting time is one of the crucial factors for patient's satisfaction and reason for leaving or returning to the same dentist. Studies have revealed that longer waiting time is the key reason for missed appointments or going to another dental facility. ${ }^{15}$ In our study the waiting time for appointment for majority of the patients was between $0-15$ minutes $(68 \%)$, followed by $16-30$ minutes $(22.1 \%)$. Only a few had to wait for more than 30 to 60 minutes or more.

Fifty-nine percent(59\%, N=72) of the attendants stated treatment cost was reasonable at the OPD, 
while $12.3 \%$ of the parentstreatment cost was expensive.Thirty-five parents (28.7\%) even stated treatment cost was low. Although there are a remarkable number of private dental clinics operating within Uttara Model Town and nearby areas, the expenses for dental treatment are sure to differ between the clinics and a teaching- learning Hospital. Prices for dental treatment in this hospital are considered quite reasonable by the local population. ${ }^{16}$ Treatment cost is a major factor for seeking treatment at the same facility and if the parents find the treatment expenses to be reasonable along with good treatment, they are surely getting value for money. These parents would definitely return in future and would be willing to refer other patients. ${ }^{17}$ Most of the parents said that the cleanliness of the department was satisfactory or good and majority of the participants expressed satisfaction with the overall environment of the pediatric OPD.

More than $95 \%$ of the parents said patient management skill of the attending doctor and skill of the assisting staff were'satisfactory' or 'good'. Majority of the parents expressed satisfaction with the treatment providedby the dental team rating them between 'satisfactory' (64\%) and 'good' (32\%.It is imperative that child patients are comfortable with the dental team; particularly the dentist should be compassionate and warm, so that the child feels safe and remain co-operative. Good communication skill as well as professionalism of the whole dental team is readily recognized by the parents and this would oblige them to bring their children back for follow up or treatment of any new ailment. ${ }^{4,5,10}$

We must state that this study had some limitations. It was a very basic survey with some very basic questions and small sample size. Parents' satisfaction level was reflected through the questionnaire but the child's experience at the POPD did not reflect through their answers. The open ended part of the questionnaire was also not answer by majority of the participants. Nevertheless, this survey reflected patient opinion in only one private hospital. Further study involving both private and public hospitals could reveal a comparative picture of patient satisfaction level in these two sectors.

\section{Conclusion}

The results indicate that the pediatric department of
Sapporo Dental College has been successful in achieving parents' satisfaction. Although a major portion of the participants of this survey expressed satisfaction with the overall performance of Pediatric OPD of Sapporo Dental College and Hospital, there remains room for further improvement in certain sectors, eg, waiting time, treatment cost and cleanliness of the department.

There should be no space for self-satisfaction even if parents visited the hospital by word of mouth; It is the quality of service that really matters. A satisfied parent would recommend more patients and this commercial success should be ensured only by sincere and patient oriented dental care delivery system.Though health of the patient remains the top most priority of the care giver, satisfaction with the care provided would always be an integral part of overall health of the client.

\section{References}

1. Patel JY. A study on evaluation of patient satisfaction with dental health care services. Int J Sci\& Res 2014; 4(8): 1-4 2. Bhat N, Sultan $P$, Chhabra $S$ et al. Assesment of patient satisfaction towards dental care services of patients visiting dental schools in Udaipur, Rajsthan, India. ICJOR 2017; 5(1): 34-41

3. Holt V, Mc Hugh K. Factors influencing patients' loyalty to dentists and dental practice. Br Dent JS 1997; 183: 365-70

4. Zimmerman R. The dental appointment and the patient behavior: Difference in patient and practitioner preferences,satisfaction And adherence. Med Care 1988; 26:403-414 5. Nagappan N, John J. Patient satisfaction with the dental services offered by a dental Hospital in India. J Indian Assoc Public Health Dent 2014; 12:297-301

6. Katre AN. Assessment of the Correlation between Appointment Scheduling and Patient Satisfaction in a Pediatric Dental Setup. Int J Dentistry 2014 (Dec): 1-7. http://dx.doi.org/10.1155/2014/453237

7. Bankole OO, Taiwo JO. Quality of care at a pediatric dental clinic in Ibadan, Nigeria. Niger J ClinPract 2013; 16:5-11

8. Tellez M, Kaur S. Caregivers' satisfaction with Pedodontic dental care in a University Clinical setting in North Philadelphia. J Dent Edu 2013;77(11): 1515-1520

9. Ali DA. Patient satisfaction in dental healthcare centers. Eur J Dent 2016; 10:309-14. Available from: http://www.eurjdent.com/text.asp?2016/10/3/309/184147 
10. AIMutairi MA. Parents' satisfaction with pediatric dental care provided by dental college, Riyadh. J IntSoc Prevent Community Dent 2016;6:542-8

11. Nwoso BC, Princess CC. Caregiver's perception of the quality of child healthcare services in a General Hospital in Lagos State. J Pub Health Epid 2015; 7(2): 29

12. Source : Bangladesh Medical \& Dental Council website: bmdc.org.bd

13. Source : Thana-Wikipedia. Website https//en.m.wikipedia.org > wiki>uttara

14. Khan MAI et al. Dental Treatment of Pediatric Patients at Sapporo Dental College. J Cont Dent Sci 2015; 3(1): 14-17

15. Sun et al. Reducing waiting time and raising outpatient satisfaction in a Chinese Public tertiary general hospital-an interrupted time series study. BMC Public Health 2017; 17:668

16. Chowdhury MTH, Nath SK, Mahbuba S, Podder CP. Level of patient satisfaction among those attending Out Patient Department of a Dental College in Dhaka- A survey. J Cont Dent Sci 2014; 2(1): 25-28

17. Patil V, Chhabra S, Rajpurohit L, Deshpande R, Kakuth A, Patil D. Assessment of Standards for quality dental Treatment and facilities provided for a child patient in a specialized Pediatric Dental Clinic. J Dent Res \&Sci 2016; 3(2): $7-11$ 